\title{
Selective Breeding of Japanese Quails for Improvement of Performance
}

\author{
Krishna Daida ${ }^{1}$ and M. Sahitya Rani ${ }^{2}$ \\ ${ }^{1}$ Department of Poultry Science, College of Veterinary Science, Korutla, \\ Jagityal -505326, Telangana, India \\ ${ }^{2}$ Department of Livestock Products Technology, College of Veterinary Science, Korutla, \\ Jagityal-505326, Telangana, India \\ *Corresponding author
}

\section{A B S T R A C T}

An experiment was conducted to study the effect of selective breeding of Japanese quails for improvement of performance. A total of 2765 quails were procured from Poultry Experimental Station as baseline population based on their body weight. Out of which 1850 quails with higher body weights were selected as parents to produce 1200 progeny quail chicks. The overall growth performance such as body weight, body weight gain and

\section{Keywords}

Japanese quail, Selection, Growth performance, Progeny, Hen day egg production

Article Info

Accepted:

20 March 2017

Available Online:

10 April 2017 feed conversion ratio parameters were recorded weekly intervals till the birds attain six weeks of age, sex wise. The body weight of the progeny $(214.09 \pm 0.75 \mathrm{~g})$ obtained from baseline and selected female quail population $(211.72 \pm 0.0975 \mathrm{~g}, 213.04 \pm 1.233 \mathrm{~g}$ respectively) was found to be higher than the parental population body weights at the end of the growth period. Similarly, the body weight gain was found to be higher in the progeny $(38.68 \pm 0.65 \mathrm{~g})$ than the parental population $(37.72 \pm 1.027 \mathrm{~g}, 37.15 \pm 0.882 \mathrm{~g}$ respectively) at six weeks of age. The feed conversion ratio of the progeny ranged from $1.89 \pm 0.02$ (first week) to $4.73 \pm 0.07$ (sixth week) which was found to be better feed conversion ratio compared with baseline and selected population during the growth period. The body weight and body weight gain of the progeny $(212.88 \pm 0.91 \mathrm{~g}$ and $34.64 \pm 0.52 \mathrm{~g}$ respectively) obtained from baseline and selected male quail population was also found to be higher than the parental population. The FCR of the progeny ranged from first week $(2.36 \pm 0.04)$ to six weeks $(5.17 \pm 0.07)$ of age. Age at first egg in the flock was 55.79 to 56.53 days and $50 \%$ of the birds came to egg production on $59^{\text {th }}$ day. The percentage of hen day egg production was $31.236,69.911$ and $54.812 \%$ eggs in $16^{\text {th }}, 32^{\text {nd }}$ and $46^{\text {th }}$ week respectively. At the age of $17^{\text {th }}$ to $32^{\text {nd }}$ weeks the hen day egg production reached peak, later the production was decreased.

\section{Introduction}

Japanese quail (Coturnix Coturnix Japonica) is a popular commercial line. Quails can be used for meat production within a short period (4-5weeks) and matures at an early age of 6 weeks so that female birds are usually in full production by about 8 weeks (Jatoi et al., 2013). Selective breeding is the most important technique, to improve the genetic potential of birds in a given set of environmental conditions (Hussain et al., 2013). Selective breeding is found to be a major tool behind the significant improvement in growth rate and carcass yield of indigenous breeds (Bhatti and Sahota, 
1994; Bhatti et al., 1992). In any genetic improvement program, body weight is one of the most important traits for a number of reasons including its relation with other meat production traits and its relative ease of measurement (Caron et al., 1990). It is further stated that the most significant trait for evaluating different livestock species especially in meat production environment is growth. It can be enhanced by improving environmental aspects such as feed, housing, management etc. and by choosing the suitable mating system, sex ratio and parental age and by improving its genotypic value by selection and/or by cross breeding (Parks, 1971). Continuous inbreeding, uncontrolled mating and poor knowledge of selective breeding are considered to be the main factors behind the deterioration in the production performance of quails (Jatoi et al., 2013).

\section{Materials and Methods}

An experiment on selective breeding of quails for improvement of performance was conducted at Poultry Experimental Station, College of Veterinary Science, Hyderabad. A total of 2765 quails were procured from Poultry Experimental Station as baseline population based on their body weight. Out of which 1850 quails with higher body weights were selected as parents to produce 1200 progeny quail chicks. Chicks were maintained under standard managemental conditions.

The overall growth performance such as body weight, body weight gain and feed conversion ratio parameters were recorded weekly intervals till the birds attain six weeks of age in all three populations sex wise. The traits measured were age at first egg (AFE) and $50 \%$ of the egg production. The percentage of hen day egg production was recorded in the $16^{\text {th }}, 32^{\text {nd }}$ and $46^{\text {th }}$ week respectively. Statistical analysis of the traits studied was done as per Snedecor and Cochran (1989).

\section{Results and Discussion}

\section{Female quail birds' performance}

The body weights of the baseline, selected and progeny population from day old to 6 weeks of age were ranged from $8.10 \pm 0.089 \mathrm{~g}$ to $\quad 211.72 \pm 0.097 \mathrm{~g}, \quad 7.93 \pm 0.116 \mathrm{~g}$ to $213.04 \pm 1.233 \mathrm{~g}$ and $8.01 \pm 0.07 \mathrm{~g}$ to $214.09 \pm 0.75 \mathrm{~g}$, respectively (Table 1). The bodyweight gain of the progeny was found to be higher at 3 weeks of age $(50.29 \pm 0.94 \mathrm{~g})$ and at the end of six weeks of age the body weight gain of progeny was observed to be $38.68 \pm 0.65 \mathrm{~g}$ compared with selected population $(37.15 \pm 0.88 \mathrm{~g})$ and $37.72 \pm 1.03 \mathrm{~g}$ in baseline population (Table 2). The feed conversion ratio of the progeny ranged from $1.890 \pm 0.02$ at first week of age to $4.731 \pm 0.07$ at 6 weeks of age compared to selected population which ranged from $1.823 \pm 0.031$ to $5.806 \pm 0.136$ and baseline population which ranged from $1.951 \pm 0.025$ first week to $5.88 \pm 0.157$ at six week of age (Table 3 ).

\section{Male quail birds' performance}

The body weights of the baseline population, selected population and progeny were found to be $7.926 \pm 0.124,8.104 \pm 0.14$ and $8.00 \pm 0.09$ $\mathrm{g}$ at day old and increased to $205.93 \pm 1.282 \mathrm{~g}$, $206.72 \pm 1.336 \mathrm{~g}$ and $212.88 \pm 0.91 \mathrm{~g}$ at six weeks of age, respectively (Table 4). The body weight gain and feed conversion ratio of the progeny were ranged from $17.14 \pm 0.26 \mathrm{~g}$ to $34.64 \pm 0.52 \mathrm{~g}$ and $2.36 \pm 0.04$ to $5.17 \pm 0.07$ at first week of age to six weeks of age, respectively compared with selected population $(17.45 \pm 0.393 \mathrm{~g}$ to $31.76 \pm 1.017 \mathrm{~g}$ and $2.388 \pm 0.05$ to $7.095 \pm 0.169$ from first week to six weeks of age) and baseline population $(16.79 \pm 0.343 \mathrm{~g}$ to $30.01 \pm 0.683 \mathrm{~g}$ and $2.34 \pm 0.06$ to $7.151 \pm 0.258$ from first week and to six weeks of age) as shown in tables 5 and 6 respectively. 
Table.1 Body weight (g) of female Japanese quail birds from 0 to $6^{\text {th }}$ week

\begin{tabular}{|l|c|c|c|c|c|c|c|}
\hline & $\mathbf{0}$ wk & $\mathbf{1 w k}$ & $\mathbf{2}^{\text {nd }} \mathbf{W k}$ & 3rd Wk & 4th Wk & 5th Wk & 6th Wk \\
\hline $\begin{array}{l}\text { Base line } \\
\text { population }\end{array}$ & $8.10 \pm 0.089$ & $26.75 \pm 0.271$ & $48.18 \pm 1.144$ & $98.78 \pm 1.251$ & $\begin{array}{c}139.73 \pm 1.45 \\
3\end{array}$ & $174.0 \pm 1.322$ & $211.72 \pm 0.0975$ \\
\hline $\begin{array}{l}\text { Selected } \\
\text { population }\end{array}$ & $7.93 \pm 0.116$ & $28.10 \pm 0.372$ & $49.80 \pm 0.788$ & $96.66 \pm 0.963$ & $\begin{array}{c}141.62 \pm 1.59 \\
3\end{array}$ & $175.89 \pm 1.45$ & $213.04 \pm 1.233$ \\
\hline Progeny & $8.01 \pm 0.07$ & $27.38 \pm 0.23$ & $69.78 \pm 0.74$ & $113.33 \pm 1.48$ & $140.67 \pm 1.07$ & $175.41 \pm 0.95$ & $214.09 \pm 0.75$ \\
\hline
\end{tabular}

Table.2 Body weight gain (g) of female Japanese quail birds from $0-6^{\text {th }}$ week

\begin{tabular}{|c|c|c|c|c|c|c|c|}
\hline & $\mathbf{0}$ wk & 1wk & $\mathbf{2}^{\text {nd }} \mathbf{W k}$ & 3rd Wk & 4th Wk & 5th Wk & 6th Wk \\
\hline Base line population & - & $20.18 \pm 0.259$ & $40.45 \pm 1.124$ & $50.59 \pm 1.3$ & $40.96 \pm 1.232$ & $34.27 \pm 1.057$ & $37.72 \pm 1.027$ \\
\hline Selected population & - & $21.77 \pm 0.346$ & $41.87 \pm 0.78$ & $46.86 \pm 1.116$ & $44.97 \pm 1.493$ & $34.27 \pm 0.853$ & $37.15 \pm 0.882$ \\
\hline Progeny & - & $20.94 \pm 0.22$ & $41.20 \pm 0.71$ & $50.29 \pm 0.94$ & $42.86 \pm 0.96$ & $34.74 \pm 0.67$ & $38.68 \pm 0.65$ \\
\hline
\end{tabular}

Table.3 Feed conversion ratio of female Japanese quail birds from 0 to $6^{\text {th }}$ week

\begin{tabular}{|l|c|c|c|c|c|c|c|}
\hline & $\mathbf{0}$ wk & 1wk & $\mathbf{2}^{\text {nd }} \mathbf{W k}$ & 3rd Wk & 4th Wk & 5th Wk & 6th Wk \\
\hline Base line population & - & $1.951 \pm 0.025$ & $1.981 \pm 0.047$ & $2.14 \pm 0.092$ & $\begin{array}{c}3.631 \pm 0.12 \\
7\end{array}$ & $5.67 \pm 0.173$ & $5.88 \pm 0.157$ \\
\hline Selected population & - & $1.823 \pm 0.031$ & $1.821 \pm 0.032$ & $2.201 \pm 0.061$ & $\begin{array}{c}3.324 \pm 0.12 \\
1\end{array}$ & $5.514 \pm 0.23$ & $5.806 \pm 0.136$ \\
\hline Progeny & - & $1.89 \pm 0.02$ & $1.91 \pm 0.03$ & $2.42 \pm 0.07$ & $3.49 \pm 0.09$ & $4.26 \pm 0.05$ & $4.73 \pm 0.07$ \\
\hline
\end{tabular}


Table.4 Body weight ( $\mathrm{g}$ ) of male Japanese quail birds from 0 to $6^{\text {th }}$ week

\begin{tabular}{|l|c|c|c|c|c|c|c|}
\hline & $\mathbf{0 ~ W k}$ & $\mathbf{1 ~ W k}$ & $\mathbf{2 ~ W k}$ & $\mathbf{3 ~ W k}$ & $\mathbf{4 ~ W k}$ & $\mathbf{5 W k}$ & $\mathbf{6 ~ W k}$ \\
\hline $\begin{array}{l}\text { Base line } \\
\text { population }\end{array}$ & $7.926 \pm 0.124$ & $25.16 \pm 0.388$ & $54.04 \pm 0.966$ & $98.82 \pm 1.163$ & $141.49 \pm 1.406$ & $174.17 \pm 1.509$ & $205.93 \pm 1.282$ \\
\hline $\begin{array}{l}\text { Selected } \\
\text { population }\end{array}$ & $8.104 \pm 0.14$ & $24.90 \pm 0.372$ & $50.71 \pm 0.905$ & $93.66 \pm 1.093$ & $141.85 \pm 1.52$ & $176.71 \pm 1.386$ & $206.72 \pm 1.336$ \\
\hline Progeny & $8.0 \pm 0.09$ & $25.03 \pm 0.27$ & $52.47 \pm 0.67$ & $96.39 \pm 0.82$ & $141.66 \pm 1.03$ & $178.24 \pm 0.98$ & $212.88 \pm 0.91$ \\
\hline
\end{tabular}

Table.5 Body weight gain (g) of male Japanese quail birds from 0 to $6^{\text {th }}$ week

\begin{tabular}{|l|c|c|c|c|c|c|c|}
\hline & $\mathbf{0 ~ W k}$ & $\mathbf{1 W k}$ & $\mathbf{2}^{\text {nd }} \mathbf{W k}$ & 3rd Wk & 4th Wk & 5th Wk & 6th Wk \\
\hline Base line population & - & $16.79 \pm 0.343$ & $25.81 \pm 0.911$ & $42.95 \pm 0.983$ & $48.19 \pm 1.186$ & $34.85 \pm 1.034$ & $30.01 \pm 0.683$ \\
\hline Selected population & - & $17.45 \pm 0.393$ & $28.88 \pm 1.062$ & $44.79 \pm 1.231$ & $42.67 \pm 1.377$ & $32.68 \pm 1.188$ & $31.76 \pm 1.017$ \\
\hline Progeny & & $17.14 \pm 0.26$ & $27.43 \pm 0.71$ & $43.92 \pm 0.80$ & $45.26 \pm 0.94$ & $36.58 \pm 0.71$ & $34.64 \pm 0.52$ \\
\hline
\end{tabular}

Table.6 Feed conversion ratio of male Japanese quail birds from 0 to $6^{\text {th }}$ weeks

\begin{tabular}{|l|c|c|c|c|c|c|c|}
\hline & $\mathbf{0 ~ W k}$ & $\mathbf{1 ~ W k}$ & $\mathbf{2 ~ W k}$ & $\mathbf{3 ~ W k}$ & $\mathbf{4 ~ W k}$ & $\mathbf{5 W k}$ & $\mathbf{6 ~ W k}$ \\
\hline Base line population & - & $2.34 \pm 0.06$ & $2.866 \pm 0.09$ & $2.432 \pm 1.406$ & $3.211 \pm 0.127$ & $5.958 \pm 0.181$ & $7.151 \pm 0.258$ \\
\hline Selected population & - & $2.388 \pm 0.05$ & $3.11 \pm 0.087$ & $2.354 \pm 0.058$ & $2.857 \pm 0.066$ & $5.458 \pm 0.199$ & $7.095 \pm 0.169$ \\
\hline Progeny & & $2.36 \pm 0.04$ & $2.98 \pm 0.06$ & $2.39 \pm 0.07$ & $3.04 \pm 0.08$ & $4.25 \pm 0.06$ & $5.17 \pm 0.07$ \\
\hline
\end{tabular}


Table.7 The mean percentage of hen day egg production of quails birds

\begin{tabular}{|l|c|c|c|}
\hline \multirow{2}{*}{\multicolumn{1}{c|}{ Age }} & \multicolumn{3}{|c|}{$\%$ HDEP } \\
\cline { 2 - 4 } & $\mathbf{1 6}^{\text {th }}$ Week & $\mathbf{3 2}^{\text {nd }}$ Week & $\mathbf{4 6}^{\text {th }}$ Week \\
\hline Mean \% HDEP & 31.236 & 69.911 & 54.812 \\
\hline SEM & 0.824 & 0.370 & 0.867 \\
\hline N & 600 & 600 & 600 \\
\hline
\end{tabular}

Age at first egg in the flock was 55.79 to 56.53 days and $50 \%$ of the birds came to egg production on 59th day. Average hen day egg production was $31.236,69.911$ and $54.812 \%$ eggs in the16th, 32nd and 46th week respectively. At the age of 17 th to 32 nd weeks the hen day egg production reached peak, later the production was decreased (Table 7).

The progeny showed improved body weights which might be due to the positive response of selection resulting in higher body weight as a response to selection (Hussain et al., 2013). Similarly improved body weight in Japanese quail was also observed in birds selected for higher body weight in many other studies as well (Baylan et al., 2009; Syed Hussein et al., 1995; Tozluca, 1993; Nestor et al., 1982). Anthony et al., (1996) observed that selected lines of Japanese quail produced heavier carcasses and more meat. Hussain et al., (2016), observed that that the selected group birds showed significantly higher average daily and cumulative feed intake which resulted in higher bodyweights. Khaldari et al., (2010) recorded a improved genetic gain of body weight through selection process, in Japanese quails.

Higher body weight in selected birds were also reported in other studies as well (Siegel, 1987), Anthony et al., (1986), Collins and Abplanalp (1968) and Marks (1975). Higher daily and cumulative feed intake in selected birds may be due to their body size as well as increased egg weight as a result of selection for body weight (Hassan et al., 2008). In a very recent study Akram et al., (2012) observed significant differences between two generations (G0 and G1) of Japanese quail being selected for higher four week body weight through selection procedures. Anthony et al., (1986) observed the higher body weight gain in selected birds as compared to random breeds. Khaldari et al., (2010) also observed better FCR in three selective generations of Japanese quail. Best FCR to a certain body weight could be partially due to lower maintenance costs and lower fat deposition of birds with higher growth rate (Pym, 1990).

Selection for better FCR in broiler chickens resulted in direct selection for carcass leanness (Buyse et al., 1999). Hussain et al., (2016) observed the age at first egg was about (47.75 \pm 1.339 days) in selection birds of G2. It might be attributed to the genetic make-up of the birds, their overall body conditions and the seasonal variations in day length because the onset of egg production is considered a combined factor of chronological age, overall body condition and day length (Krapu, 1981; Reddish et al., 1993).

In conclusion the present study showed that the growth and production performance can be enhanced through selection process. The body weight was increased as age increases in both male and female quail population. Body weight gain increased up to 3 weeks and there after it decreased in both populations under study. Feed efficiency was better in earlier ages and it decreases as the age progress. Peak egg production was observed at 32 weeks of age there after it decreases. 


\section{References}

Akram, M., J. Hussain, A. W. Sahota, S. Ahmad, A. S. Jatoi, A. Ali, and Dawood M. 2012. Genetic gain in 4 week body weight through mass selection in 4 close-bred stocks of Japanese quail. Book of abstracts. 32nd Congress of Zoology, Lahore, Pakistan.

Anthony, N. B., K. E. Nestor and Marks H. L. 1996. Short-term selection for fourweek body weight in Japanese quail. Poult. Sci., 75:1192-1197.

Anthony, N. B., K. E. Nestor and Bacon W. L. 1986. Growth curves of Japanese quail as modified by divergent selection for 4 - week body weight. Poult. Sci., 65:1825 - 1833.

Baylan, M., S. Canogullari, A. Sahin, G. Copur and Baylan M.2009. Effect of different selection methods for body wegiht on some genetic parameters. J. Anim. Vet. Adv., 8:1385-1391.

Bhatti, B. M. and Sahota, A. W. 1994. Growth performance and carcass quality of different crosses of chickens. Pakistan Vet. J., 14:250-253.

Bhatti, M. A., M. S. Qureshi and Ahmed A. 1992. Comparative study on the performance of various genetic groups of Aseel and its crosses with exotic breeds of poultry under controlled and field conditions. Pages 4-6, 17 in Second Annual Report (1990-1991) of Pakistan Agric. Res. Council, Project.Res. Council, Project.

Buyse, J., F. R. Leenstra, M. Zeman, G. Rahim and Decuypere E. 1999. A comparative study of different selection strategies to breed leaner meat-type poultry. Poult. Avian Biol. Rev., 10:121-142.

Caron, N. F., M. Minvielle, Desmarais and Poste L. M. 1990. Mass Selection for 45-Day Body Weight in Japanese
Quail: Selection Response, Carcass Composition, Cooking Properties, and Sensory Characteristics. Poult. Sci., 69:1037-1045.

Collins, W. M. and Abplanalp, H.1968. Changes in body weight and organ weights of Japanese

quail selected for 6 - week body weight. Brit.Poult. Sci., 9:231-242.

Hassan, M.M., E. Haq, and Ahmad F. 2008. Effect of age and body weight at molting on the

performance of broiler breeder hens under environmental control houses in Pakistan. Pakistan Vet. J. 28(4):189193.

Hussain, J., M. Akram, K. Javed, H. A. Ahmad, A. Mahmud, S.Mehmood, S. Ahmad, F. Ahmad, A. S. Jatoi, Y. Abbas and Hussnain. F. 2016. Quail Breeder's Production Performance In Response To Selection For Higher Three Weeks Body Weight. The Journal of Animal \& Plant Sciences, 26(3): Page:588-593 ISSN: 10187081.

Hussain, J., M. Akram, A. W. Sahota, K. Javed, H.A. Ahmad, S. Mehmood, S. Ahmad, R. Sulaman, I. Rabbani and Jatoi A. S.2013. Selection for higher three week body weight in japanese quail: 1. effect on growth performance. The Journal of Animal \& Plant Sciences, 23(6): 2013, Page: 1496-1500 ISSN: 1018-7081

Jatoi, A. S., A. W. Sahota, M. Akram, K. Javed, M. H. Jaspal, J. Hussain, A. H. Mirani and Mehmood S. 2013. Effect of Different Body Weight Categories on the Productive. The J. Anim. \& Plant Sciences., 23(1):7-13.

Khaldari, M. A., H. Pakdel, Mehrabani Yegane, A. Nejati Javaremi and Berg P. 2010. Response to selection and genetic parameters of body and carcass weights in Japanese quail 
selected for 4-

Week body weight. Poult. Sci., 89:18341841.

Krapu, G.L., 1981. The role of nutrient reserves in mallard reproduction. Auk. 98:29-38.

Marks, H. L., 1975. Relationship of embryonic development to egg weight, hatch weight and

growth in Japanese quail. Poult. Sci., 54:2571262.

Nestor, K., and Bacon, W. L. 1982. Divergent selection for body weight and yolk precursor in Cotournix cotournix Japonica. 3. Correlated responses in mortality, reproduction traits and adult body weight. Poult. Sci., 612137 2142.

Pym, R. A. E., 1990. Nutritional genetics. In Poultry Breeding and Genetics. R. D. Crawford Elsevier ed., Oxford, UK.

Reddish, J.M., K.E. Nestor, and Lilburn M.S. 1993. Effect of selection for growth on onset of sexual maturity in random bred and growth-selected lines of Japanese quail. Poult. Sci. 82:187-191.

Siegel, P. B., 1987. Response to twenty generations of selection for body weight. Pages 1761-1772 in XVI World's Poult. Cong., Riode Janeiro, Brazil.

Snedecor, G.W., and Cochran, W.G. 1989. Statistical Methods. 8th Ed. Ames: Iowa State Press.

Syed Hussein, S. A., Y. S. Chee and Jamilah M. 1995. Selection of quail for meat prodcution. Proc. Malays. Soc. Anim. Pro., Penang, Malaysia. Malyasian Society of Animal Production, Serdang, Selangor, Malaysia.

Tozluca, A., 1993. Productvity of selection according to body weight in different nutrition condidtion and the effects on the ohters production paramerters in Japaese quail. PhD. Univ. Selcuk, Turkey.

\section{How to cite this article:}

Krishna Daida and M. Sahitya Rani. 2017. Selective Breeding of Japanese Quails for Improvement of Performance. Int.J.Curr.Microbiol.App.Sci. 6(4): 2500-2506. doi: https://doi.org/10.20546/ijcmas.2017.604.291 